\title{
El gaucho de América. El raíd de Marcelino Soulé, de Buenos Aires a Washington, 1938-1942
}

\section{The America's gaucho.}

Marcelino Soulé's raide, from Buenos Aires to Washington, 1938-1942

Matías Emiliano Casas

Programa de Historia Cultural

Universidad Nacional de Tres de Febrero - CONICET

Argentina

matiasemiliano@hotmail.com

Recibido 8 de mayo 2015 Aceptado: 27 de setiembre 2015

http://dx.doi.org/10.15359/tdna.31-58.2

\section{Resumen}

La figura del gaucho fue objeto de múltiples atribuciones de sentido desde el siglo XVIII hasta la actualidad. Disímiles representaciones circularon simultáneamente dando lugar a una puja de significados que se manifestó con particular intensidad en la década del cuarenta en la provincia de Buenos Aires. En ese contexto, el viaje a caballo realizado por Marcelino Soulé, autoproclamado "gaucho argentino", aporta una serie de elementos que

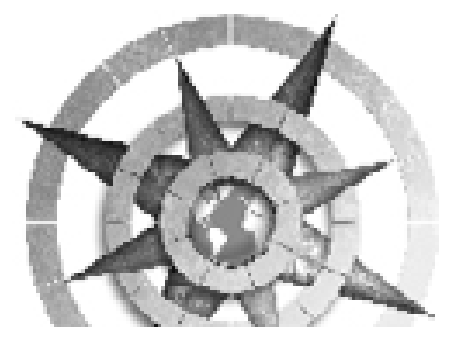

permiten ampliar el análisis de estas construcciones incorporando en el estudio a diversos países de la región americana. La colección de periódicos que se encuentran en su archivo personal posibilita la reconstrucción de su aventura: desde arquetipo de la argentinidad hasta sinónimo de cowboy, el extenso recorrido transitado daba cuenta de la labilidad del "gaucho". Soulé fue reconstruyendo su propia representación a medida que se alejaba de Buenos Aires. Las crónicas periodísticas que reproducen su viaje complementaron este proceso reconociéndolo como genuino portador de las tradiciones argentinas.

Palabras clave: gaucho, tradición, Marcelino Soulé, prensa americana, Raid, identidad nacional argentina 


\section{Abstract}

Since the 18th. century to the date, the character of the gaucho has been subject of several attributions of meaning. The gaucho's different representations circulated simultaneously, resulting in different meanings for this character which were expressed with particular intensity in the decade of the 40's in the Province of Buenos Aires. In this context, the horseback ride done by Marcelino Soulé, a self-proclaimed Argentine gaucho, provides a number of elements to deepen the analysis on such representations and incorporating into the study several countries in the Americas. The collection of newspapers found in Solé's personal file, allows a reconstruction of his adventure. From the archetype of argentinidad --as the most importat of the Argentine's heritage symbols-- up to a synonymous for the cow-boy, the extensive route traveled by Soulé allows us to realize the gaucho's lability. Soulé re-built his own story as soon as he was leaving Buenos Aires. The role played by the media on reporting his ride, complemented the process of recognozing him as a genuine bearer of the Argentina's tradition.

Keywords: gaucho, tradition, Marcelino Soulé, american press, Argentine national identity - Ride

\section{Resumo}

Desde o século XVIII até o presente, o gaúcho tem várias atribuições de sentido. As representações circularam simultaneamente com significados vários mais foram expressas com particular intensidade nos anos quarenta, na província de Buenos Aires. Neste contexto, o passeio a cavalo por Marcelino Soulé, auto-proclamado «gaucho argentino», fornece um número de elementos que ampliam a análise dessas representações com incorporação de diversos países americanos em neste estudo. A coleção de papéis no arquivo pessoal de Solé permite a reconstrução de sua aventura. A partir do arquétipo do argentinidad, o símbolo mais importante do legado de Argentina, o chegar ao sinônimo de cowboy, a extensa turnê de Solé apresenta a labilidade do «gaucho». Soulé criou sua própria imagem quando deixou Buenos Aires. As reportagens de jornais que reproduzem sua viagem foi um complemento a este processo reconhecendo-o como verdadeiro portador das tradições argentinas.

Palavras chave: Gaucho, tradição, Marcelino Soulé, imprensa americana, identidade nacional argentina, turnê

La figura del gaucho fue objeto de múltiples atribuciones de sentido desde el siglo XVIII hasta la actualidad. Disímiles representaciones circularon simultáneamente dando lugar a una puja de significados que se manifestó con intensidad en la década del cuarenta en la Provincia de Buenos Aires. Para esa época, una suerte de "apropiación estatal" de la

34 El gaucho de América. El raíd de Marcelino Soulé, de Buenos Aires a Washington, 1938-1942 Matías Emiliano-Casas 
figura del gaucho dio origen a diversas medidas que decretaron la evocación de éste como arquetipo de la nacionalidad argentina (Cattaruzza y Eujanian, 2003). La sanción de la Ley 4.756 instituyó por unanimidad el Día de la Tradición a celebrarse cada 10 de noviembre en homenaje a José Hernández, autor del Martín Fierro. En esa efeméride se condensaron las reivindicaciones que los criollistas recuperaban desde finales del siglo XIX (Prieto, 1988). Los primeros festejos orgánicos de la tradición representaron la celebración oficial del gaucho y las costumbres rurales (Casas, 2014).

En esa coyuntura, la provincia de Buenos Aires era gobernada por el nacionalista conservador Manuel Fresco, quien había sido elegido como máxima autoridad provincial hacia mediados de la década del treinta en elecciones fraudulentas. Esa característica, sumadas a las continuas acusaciones de corrupción, le imposibilitaron consolidarse como figura aglutinante del nacionalismo argentino (Buchrucker, 1999). El Gobierno de Fresco, a través de su Ministro de Obras Públicas, el ingeniero José María Bustillo, respaldaba explícitamente la reivindicación del gaucho como arquetipo de la tradición nacional. Esa narrativa se insertaba en la permanente preocupación por cristalizar los lazos identitarios argentinos, siempre "amenazados".

La amenaza, en el contexto de las primeras Fiestas de la Tradición, estuvo atravesada por la coyuntura de los inicios de la Segunda Guerra Mundial. Ese conflicto internacional fue aludido, de modo sutil y tangencial, en las primeras celebraciones. La efeméride adquirió, desde su sanción, connotaciones nacionalistas en tanto los discursos circulantes allí se afanaban en "cerrar filas" y cristalizar una "identidad argentina" en detrimento del cosmopolitismo y las influencias extranjeras. La dicotomía no se fundamentaba tanto, hacia 1939, en la vitalidad de las corrientes inmigratorias. De hecho, la inmigración a la Argentina había disminuido un 75 por ciento -en un promedio aproximado- respecto de la década anterior. Como plantea Fernando Devoto, desde la segunda mitad de la década del treinta el "problema migratorio" se planteaba desde otras perspectivas. La cuestión de los refugiados generaba álgidos cuestionamientos en la política internacional e interna. Las elites conservadoras que gobernaban el país rechazaban su llegada alegando que -en tanto no eran desplazamientos voluntarios- los refugiados mostraban serias limitaciones en sus capacidades productivas 
y escasa motivación para integrarse (Devoto, 2001).

La preocupación por las inmigraciones no deseadas emergió con intensidad, tanto al comienzo de la guerra civil española en 1936 como en los inicios de la contienda bélica mundial en los meses previos a la realización de la primera Fiesta de la Tradición (Senkman, 1991; Schwarztein, 1997). De ese modo, las prédicas tradicionalistas se articulaban con un contexto político funcional para la exaltación de lo "nacional" y la animadversión hacia lo "foráneo".

En el marco de la dicotomía país rural-país urbano, se operaba identificando al campo con los valores de la argentinidad y a la ciudad-puerto con el cosmopolitismo "disolvente" (Ballent y Gorelik, 2001). Se multiplicaron así, los discursos que clamaban la "urgencia" por rescatar las costumbres olvidadas para hacer frente a las ideas ideologías foráneas. El ministro Bustillo en la primera Fiesta de la Tradición declaró: "un país nuevo, que recibe corrientes inmigratorias de todos los rumbos, sufre, naturalmente, influencias extrañas que van esfumando su fisonomía individual."1

$1 \quad$ La Gaceta, 26 de noviembre de 1939.
Inmerso en el clima de época, sintetizado así para fines de los años treinta, Marcelino Soulé, un profesor de polo y equitación oriundo de la ciudad de Bolívar, en el interior de la Provincia de Buenos Aires, decidió lanzarse a recorrer el continente en un raíd hípico que lo llevaría desde su ciudad natal hasta la capital de Estados Unidos. El viaje a caballo realizado por ese autoproclamado "gaucho argentino" aporta una serie de elementos que permiten analizar la construcción y reconstrucción de una representación particular del gaucho y poner de relieve la recepción de la prensa americana que se hacía eco de su aventura. Sin embargo, no es menester de este artículo profundizar en las características ni en los componentes de las publicaciones gráficas que le otorgaron un espacio al "gaucho" entre sus páginas. Más que un trabajo sobre la historia de la prensa, se pretende contribuir a los estudios sobre la figura del gaucho, en este caso particular desde su difusión en el exterior.

Esta investigación se abastece de la colección de periódicos que se encuentran en el archivo personal de Marcelino Soulé, sus notas de viaje, su libro de firmas y las fotografías retratadas. Ese acervo no solo posibilita la reconstrucción de su viaje

36 El gaucho de América. El raíd de Marcelino Soulé, de Buenos Aires a Washington, 1938-1942 Matías Emiliano-Casas 
y contrasta los recurrentes errores de información en los que incurrían numerosos matutinos, sino que contribuye a investigar qué imagen del gaucho se difundía en los diferentes países.

Desde arquetipo de la argentinidad hasta sinónimo de cow-boy, disímiles interpretaciones se esbozaron sobre la figura del gaucho. Soulé contribuyó con esas "tergiversaciones" a partir de las mutaciones en sus discursos. Empero, su aventura aún se recuerda en los ámbitos tradicionalistas. En las Fiestas de la Tradición de 2013, los bolivarenses colocaron una plaqueta en la plaza de Hale y realizaron una cabalgata para celebrar el 75 aniversario del raíd.

\section{Un recorrido tergiversado, las in- formaciones encontradas}

Desandar el camino de Marcelino Soulé hasta la ciudad de Washington presenta una serie de complejidades que remiten a informaciones encontradas, contradictorias entre si. No obstante, los documentos revisados permiten reconstruir su derrotero. Al desarrollar un estudio minucioso sobre cada una de las publicaciones que Marcelino iba generando a su paso, se pueden destacar tres características fundamentales: una modificación en su discurso en referencia a diversos temas, por ejemplo a su relación con los indígenas americanos o las apreciaciones sobre los diferentes países y ciudades; una continua búsqueda por explicitar las características y atributos particulares del "gaucho"; y un afán recurrente por rescatar la fuerza y el espíritu de lucha de los caballos criollos.

Las variantes discursivas de Soulé se complementan con una serie de datos contradictorios que dificultan la reconstrucción lineal del viaje realizado. El punto de partida de su extenso recorrido se encontraba en Bolivar, aproximadamente a trescientos kilómetros de la Ciudad de Buenos Aires. De acuerdo a lo testimoniado por los periódicos locales, el raíd comenzó en la plaza principal del pueblo desde donde partió con destino a Washington, el 27 de julio de 1938. La crónica de El Imparcial de Bolivar clasificaba la partida de Soulé como un verdadero suceso para el lugar, focalizando en el número de ciudadanos que acompañaron el inicio de la travesía. Además el diario precisó la colaboración de los vecinos para la obtención de sus los compañeros de viaje de Soulé: Argentino y Bolivar eran los nombres de los caballos que comenzaron el raíd con el "gaucho", donado el primero por la 
estancia La Celina de Suberbülher y obtenido el otro gracias al polista Juan Poggio. ${ }^{2}$

La participación del intendente conservador Miguel Capredoni en el momento de la partida es otro de los elementos que se destacaron en la prensa, aludiendo un firme apoyo del municipio a la propuesta. Empero, más allá de la presencia del pueblo y los funcionarios bolivarenses, ese respaldo no se tradujo en ningún tipo de soporte material al viaje que comenzaba a desarrollarse. En varias ocasiones, Marcelino Soulé se mostraba interesado en aclarar que sólo sus fondos costeaban los gastos generados. De hecho, manifestaba que mediante la venta de los mapas que iba confeccionando a su paso podía solventar las necesidades básicas cotidianas y proseguir su marcha. ${ }^{3}$

Más allá del acontecimiento que había captado la atención en Bolivar, diversos periódicos de América del Norte presentaron un punto de salida diferente. Incluso Marcelino Soulé, a partir de las citas textuales que se incluían, confirmaba una ruta extendida. Las referencias a su supuesta partida de la Patagonia se plasmaban indicando la salida desde diferentes puntos, como la provincia de Santa

2 El Imparcial, 25 de julio de 1938.

3 San Antonio Express, 7 de julio de 1940.
Cruz o el Cabo de Hornos, el sitio más austral del continente. ${ }^{4}$ Se anticipaba allí, un recurso recurrente en las descripciones del "gaucho" quien se esforzaría por agrandar su hazaña incorporando a su relato episodios incongruentes con su viaje.

Es adecuado indicar que la confusión con respecto a su partida sólo grafica una serie de numerosos errores que emergen al contrastar la información difundida en los diferentes países. El caso puntual de la Patagonia podría vincularse a la escasez de datos de los periódicos norteamericanos para precisar el recorrido de Soulé. Asimismo, en ocasiones pareció funcionar como un reduccionismo o simplificación del territorio de la República Argentina. La mirada de la prensa del norte identificaba al país austral en su totalidad con la región patagónica y así se presentaba en algunos de los títulos publicados. ${ }^{5}$

Las imprecisiones trascendieron la cuestión de la Patagonia. El periódico The Times Picayune, de New Orleans, remitía a las dificultades que

4 Esas afirmaciones se publicaron en, The Roanoke World-News, 27 de enero de 1941; Evening Public Ledger, 20 de junio de 1941.

5 "A mounted 'ambassador' from Patagonia is in San Francisco" explicaba el San Francisco Chronicle, en agosto de 1941. Referencias similaren se publicaron en Salt Lake, 11 de agosto de 1941.

38 El gaucho de América. El raíd de Marcelino Soulé, de Buenos Aires a Washington, 1938-1942 Matías Emiliano-Casas 
Marcelino Soulé había tenido que atravesar a causa de la densa nieve de la ciudad de Buenos Aires. ${ }^{6}$

El clima templado de la capital Argentina sólo cuenta con tres nevadas en su historia desde 1912. Las condiciones meteorológicas de la ciudad no presentan posibilidades de nevadas habituales, y los fenómenos registrados se caracterizan como casos extraordinarios. Ningún registro indica, la caída, ni siquiera, de agua nieve para julio de 1938, fecha de la partida del aventurero y sus caballos. Lo que parece primar en este caso es la confusión respecto al lugar donde Marcelino debió atravesar fuertes nevadas, que efectivamente representaron un obstáculo para su viaje pero no en Buenos Aires. De hecho, Soulé describió complejas dificultades para atravesar las ciudades de mayor altitud y los problemas acaecidos en sus corceles. ${ }^{?}$

La descripción en cuanto a las características y habilidades del jinete no se encontraron exentas de tergiversaciones. En algunos casos parecían remitir a una opción concreta de Marcelino Soulé con vistas a engrosar la carga emotiva y heroica de sus anécdotas. En 1940 el gaucho cruzó

6 The Times Picayune, diciembre de 1940.

7 Periódico de Nueva Laredo, México, s/n, 25 de octubre de 1941. el canal de Panamá para continuar su viaje. Para esa actividad él mismo había testimoniado el período de práctica al que se había sometido junto con Argentino y Bolivar en los márgenes del Río Salado. El cruce per se presenta sus variantes a la hora de contrastar toda la información recogida y las crónicas de los diversos países. Desde la soledad de la hazaña hasta la compañía de los navíos norteamericanos que lo protegían de los cocodrilos o tiburones dependiendo de la edición, distintas informaciones se publicaron en referencia al tema. El diario La Prensa de Texas no dudó en aseverar que el cruce efectivamente se había realizado, pero no a nado como el propio protagonista afirmaba, sino en los botes de custodia de los militares norteamericanos de presencia permanente en el lugar. ${ }^{8}$

En referencia a los atributos de Soulé, un periódico colombiano lo presentaba como profesor de natación -además de reseñar sus habilidades hípicas-. ${ }^{9}$ Sin embargo, el protagonista había afirmado que no sabía nadar y en esa incapacidad se sustentaba la proeza de sus caballos criollos que lo habrían transportado

\footnotetext{
8 La Prensa, Texas, 7 de octubre de 1940.

9 Periódico de Popayán, Colombia, s/n, 16 de agosto de 1939.
} 
al otro lado del canal de Panamá. ${ }^{10}$ Resaltar las cualidades de sus caballos constituiría una de las prioridades para Marcelino, particularmente en la segunda mitad de su recorrido.

La situación económica del raidista también delató una serie de desinformaciones, sobre todo en la prensa norteamericana. En las publicaciones más fidedignas que describen pormenorizadamente la realidad social de la familia Soulé en la ciudad de Bolivar se afirmaba su pertenencia a la clase media bonaerense. Las dificultades, tanto en la financiación del viaje como en la obtención de los dos caballos, dan cuenta de una economía familiar que no gozaba de una posición acomodada. ${ }^{11}$ Soulé se encargó en varios momentos de su recorrido de expresar lo costoso de su aventura y las dificultades de índole económicas que iba sosteniendo a su paso. Empero, el periódico Daily News de los Estados Unidos no vaciló en hacer referencia al "gaucho" como un "bussinesman". ${ }^{12}$ Como ya se ha mencionado, la problemática de la caracterización del "gaucho argentino" ha suscitado numerosas producciones historiográficas con pretensiones de establecer certezas sobre el "domador de las pampas". Para Emilio Carretero,

10 El Colombiano, 15 de agosto de 1942.

11 El Argentino, 9 de agosto de 1938.

12 Daily News, 15 de septiembre de 1941. el "Gaucho, por sobre todas las cosas es sinónimo de desposeído". Según sus estudios, un estanciero rico nunca podría considerarse gaucho: "El dueño de la estancia puede manejar caballo, lazo, boleadoras y cuchillos con tanta o más destreza que el peón y, sin embargo, no era gaucho...el gaucho estaba ubicado en posición de asalariado." (Carretero, 1964 p. 65). La identificación de Soulé con los "hombres de negocios" entraba en tensión con una de las características más consensuadas para los gauchos.

A medida que Marcelino iba avanzando en su camino, las comparaciones con Aime Tschiffely se manifestaban de modo más recurrente. Tschiffely era un profesor suizo que en 1925 había emprendido un raíd desde Buenos Aires a Washington para probar la capacidad de los caballos criollos. Sus dos compañeros durante todo el viaje fueron los que posteriormente se establecieron como símbolo de las virtudes de los corcéles argentinos y hasta el día de hoy guardan un espacio de homenaje para ellos en el Museo de Luján de la provincia de Buenos Aires. Gato y Mancha, nombres con los que habían sido bautizados, recorrieron once países y alcanzaron la finalización de la hazaña al llegar a la capital norteamericana.

40 El gaucho de América. El raíd de Marcelino Soulé, de Buenos Aires a Washington, 1938-1942 Matías Emiliano-Casas 
Pese a la aventura concretada por Tschiffelly y los puntos de contacto que emergían casi espontáneamente de la comparación entre ambos, Soulé se mostró siempre preocupado por separar su gesta de la del suizo. La primera diferenciación que enunciaba se encontraba relacionada con la originalidad de ser el primer "gaucho" en lanzarse a un raíd tan prolongado. En ese caso, Tschiffely se había encargado de aclarar: "Yo no soy un gaucho, como se les llama a los jinetes de la pampa. Soy maestro por profesión...". ${ }^{33}$ Sin embargo, en diversas ocasiones, el domador argentino desacreditó a su antecesor desde distintos argumentos. Por ejemplo, En el periódico The Reoanoke World-news, Marcelino afirmó que se había reunido con Tschiffely, a quien le reconocía haber llegado a caballo a los Estados Unidos pero le atribuía una distancia menor porque aseguraba que había salido de Bolivia. ${ }^{14}$ En otras declaraciones la diferenciación apuntaba hacia la imposibilidad del suizo de arribar a la ciudad de Nueva York sobre el lomo de sus caballos debido al intenso tránsito automotor. ${ }^{15}$ Por último,

13 "De Buenos Aires a Washington a caballo" en The National Geographic Magazine, vol LV, $\mathrm{n}^{\circ} 2$, Washington, febrero de 1929 .

14 The Roanoke world-news, 27 de julio de 1941.

15 "De Buenos Aires a Washington a caballo" en The National Geographic Magazine, vol LV, $\mathrm{n}^{\circ} 2$, Washington, febrero de 1929.
Soulé realizaba hincapié en el hecho de que todo su recorrido había sido transitado teniendo sólo como vehículos a los potros criollos, mientras que Aime Tschiffely había realizado un tramo por mar debido al inicio de la lucha armada en Nicaragua dirigida por Augusto Cesar Sandino.

Lo cierto es que más allá de los esfuerzos por diferenciarse, la asociación se encontraba recurrentemente en las crónicas periodísticas. Esa vinculación carecía de datos específicos sobre la obra de Tschiffely, hasta el punto que se lo solía mencionar como compatriota de Marcelino. Soulé usufructuó esa falta de información para reposicionarse como pionero de una práctica que tenía al docente suizo, y sus dos caballos, como máximos exponentes.

\section{Las contradicciones del gaucho}

Lo que se modificaba en orden a las informaciones publicadas, a medida que Soulé iba completando su recorrido, no sólo eran producto de las imprecisiones periodísticas sino que su propio discurso presentaba variaciones dignas de analizar. El primer elemento que se ponía de relieve es el acomodamiento ideológico que operó Marcelino acorde a los lugares que iba visitando. Cabe destacar que el raíd se realizó 
en un período de convulsión a escala global a partir del desarrollo de la Segunda Guerra Mundial. En lo referente a este punto el "gaucho argentino" mantuvo una línea de coherencia en sus opiniones: su rechazo a las políticas de Hitler no vacilaron durante la travesía. ${ }^{16}$

Además, a medida que la política de la "buena vecindad" expuesta por el presidente de los Estados Unidos, Franklin Roosevelt, se materializaba en la solidaridad exhortada a los países de América Latina ante el devenir del conflicto bélico, el "gaucho" se constituía como un manifiesto adherente de la "comunión americana". Sin embargo, a la hora de fragmentar la atención en sus declaraciones sobre los políticos de América, se advierte que su discurso se iba identificando con las doctrinas políticas más variadas, desde Anastasio Somoza en Nicaragua, pasando por Pancho Villa en México, hasta los elogios a la máxima autoridad estadounidense. ${ }^{17}$

$\overline{16 \text { Salt Lake, Utah, } 11}$ de agosto de 1941 o Periódico de Waynesboro, Virginia, 3 de febrero de 1941.

17 Sobre Somoza: "Allá sabemos que Nicaragüa es gobernada por un joven pero experto mandatario...quiere darle la mano para expresarle su admiración”. La Prensa, Nicaragua, ca. junio de 1942. Sobre Pancho Villa: "conocer el estado de Chihuahua donde operó el guerrillero Pancho Villa a quien se admira en $\mathrm{Ar}$ gentina.” Periódico de Veracruz s/n, ca. 1940.
Las vinculaciones de Marcelino Soulé con la política no permitían adherirlo -hasta ese momento- bajo una línea de pensamiento y acción orgánica. Su participación se definiría luego de su regreso a Buenos $\mathrm{Ai}$ res donde se desempeñó como funcionario del primer gobierno de Juan Domingo Perón. Su actividad en la política se remitió a la Secretaría de Trabajo y Previsión y su labor consistía en inspeccionar las estancias y los establecimientos rurales del interior de la provincia de Buenos Aires para corroborar el cumplimiento de las disposiciones en torno a los trabajadores del campo. ${ }^{18}$

Los vaivenes declarativos de Soulé en su viaje por el continente no se circunscribieron al ámbito político. Su recurrente pregón por la unidad americana se vio contrariado en varias de las descripciones que el gaucho realizó sobre las ciudades visitadas. ${ }^{19} \mathrm{El}$ ejemplo más representativo es el que delata su consideración

Sobre Roosevelt: The Knowville Journal, 18 de enero de 1941 o El Continental, 21 de octubre de 1941.

18 Algunos periódicos locales testimoniaban el recorrido de la inspección con un detalle minucioso sobre cada estancia visitada, por ejemplo El Ciudadano (de 25 de Mayo), 22 de agosto de 1946.

19 Las exaltaciones a la unidad entre los países del continente se publicaron con citas directas de Marcelino Soulé, en, The Knoville Journal, 18 de enero de 1941. El Universal, s/f. El Colombiano, 15 de agosto de 1942.

42 El gaucho de América. El raíd de Marcelino Soulé, de Buenos Aires a Washington, 1938-1942 Matías Emiliano-Casas 
hacia el territorio mexicano. En los periódicos El Universal y Página 12 de Distrito Federal, ya a su regreso de Estados Unidos, expresó que conservaba como lo más grato de su experiencia su paso por los pueblitos mexicanos. Además, comparaba: "Nueva York es una gran ciudad... pero nunca como las ciudades de más acá del Río Bravo." ${ }^{20}$ Esas afirmaciones serían rectificadas en sus entrevistas a la prensa nicaragüense.

En Managua, Soulé se mostró asombrado ante la presunta rivalidad latente entre los habitantes de ese país y los migrantes mexicanos. Repudió los letreros de los carros que esbozaban: "no nos confundan, somos mejicanos", pero lejos de pronunciarse en pos de salvar esas diferencias, sus palabras se dirigieron a plasmar lo mal que lo habían tratado en el país del norte. El gaucho expresaba: "sólo en México me recibieron francamente mal [...] "llevo un hondo reconocimiento para todas las repúblicas de América, excepto para la única nación en que me recibieron mal". ${ }^{21}$ Además, llegó a relatar un supuesto incidente que habría terminado a los golpes. Lo concreto que le había sucedido en México, y que parecía argumentar esas afirmaciones, era el robo de uno de sus

20 El Universal, ca. febrero 1940.

21 La Prensa, Nicaragua, ca. junio de 1942. caballos que lo acompañaba desde Buenos Aires. Sin embargo, en sus contactos con la prensa de ese país nunca realizó ni siquiera una breve referencia a lo expresado con tal vehemencia en Nicaragua.

Las variaciones discursivas de Soulé se manifestaron también en orden a su relación con los indígenas nativos. La cuestión del indigenismo se había presentado desde los años veinte en la literatura americana y se había instalado en las décadas posteriores principalmente con las producciones peruanas de José María Arguedas (Portugal, 2007). Desde la perspectiva política, el Primer Congreso Indigenista Interamericano realizado en Pátzcuaro, Michoacán, en 1940, representó el inicio de una serie de gestiones tendientes a intervenir en las cuestiones referidas a los habitantes originarios. ${ }^{22}$

Alejado de esos procesos de reivindicación, Marcelino acumuló una serie de calificaciones peyorativas - la mayoría publicada en los medios estadounidenses- para los indígenas americanos. En un periódico colombiano de la ciudad

22 Ver Elio Masferrer, 40 años. Índice general de América Indígena y Anuario Indigenista. 1940 - 1980, Serie SEDIAL I, Instituto Indigenista Interamericano, México, 1980, pp. XIII- XXIV 
de Cali, la entrevista se titulaba: "atacado por los indios en Bolivia", aseveración que el gaucho confirmaba en el cuerpo de la nota. ${ }^{23}$ En una crónica del diario La Nación de Trujillo manifestó que le había sido muy difícil escapar a la "salvaje furia de los indios". ${ }^{24}$ En el país presidido por Franklin Roosevelt las expresiones descalificativas adquirían una mayor intensidad: "Ignorant indians" encabezaba las publicaciones que narraban las desventuras del "gaucho" supuestamente capturado por los indígenas colombianos. ${ }^{25}$

Esas publicaciones contrastaban notoriamente con las expresiones de Soulé en territorio mexicano donde relató con añoranza el tiempo compartido con los indios en el Golfo de Darién. ${ }^{26}$ Los mismos que, según cuentó poco tiempo después en Barranquilla, le habían robado todo lo que tenía. ${ }^{27}$ De regreso en Argentina, retomó la perspectiva laudatoria para afirmar: "iQue buenos y que nobles son los indígenas americanos que viven en estado primitivo!". ${ }^{28}$ Las contradicciones de Soulé son tan extensas como su mismo

23 Periódico de Cali, s/n Colombia, ca. 1939.

24 La Nación, Trujillo, mayo de 1939.

25 San Antonio Express, 7 de noviembre de 1940.

26 El Universal, ca. 1942.

27 Periódico de Barranquilla, s/n, agosto de 1942.

28 Noticias Gráficas, 10 de enero de 1943. recorrido. Marcelino parece haber leído las condiciones de posibilidad de determinados discursos adecuándose a los lugares que visitaba y a los receptores de sus mensajes.

En el marco de la porosidad informativa que tanto el gaucho, como la prensa que difundía su raíd, confirmaban a cada paso, los equívocos se multiplicaron en relación a los acompañantes del "gaucho". La sombra de Gato y Mancha pareció ser una presión constante para el protagonista. El hecho de que fuesen dos los caballos criollos que ya habían realizado el recorrido en años anteriores parecía representar una exigencia extra para cumplir con el arriesgado trayecto. La identificación del caballo criollo con la tradición argentina tenía una larga proyección literaria. A partir de su participación en las "epopeyas" guerreras y los labores rurales se consideraba que su influjo había resultado determinante en la conformación del carácter y el "espíritu" de los argentinos (Terrera, 1969).

Las informaciones imprecisas sobre los caballos se encuentras desde momentos previos a la partida en la ciudad de Bolivar. Marcelino Soulé perdió sus dos corcées durante el raíd. El primero había fallecido por enfermedad en Colombia y el segundo fue hurtado

44 El gaucho de América. El raíd de Marcelino Soulé, de Buenos Aires a Washington, 1938-1942 Matías Emiliano-Casas 
en México. Sin embargo, Los periódicos estadounidenses presentaban al potro criollo llamado Argentino como el héroe de la aventura. El gaucho avalaba las informaciones dando cuenta del esfuerzo que había realizado el fiel acompañante a lo largo de todo el recorrido. ${ }^{29}$

$\mathrm{Su}$ discurso fue sostenido hasta el límite de sus posibilidades. En efecto, recién en su regreso a Medellín, Soulé reconoció que la aventura se había concretado gracias a un caballo paisa, antioqueño, que le habían prestado en esa ciudad colombiana. ${ }^{30}$ Las siguientes imágenes evidencian las diferencias en los caballos:

En aquella ciudad, las narraciones sobre la estirpe del caballo criollo que, supuestamente, habrían dado otra muestra de su valiosa condición atravesando América llegaban a su fin. Junto con ellas, la pretensión de exportar una imagen de resistencia y fortaleza que no sólo involucraba a lo ecuestre sino que se buscaba identificar cómo características constitutivas del "ser argentino". Luego de atravesar el territorio colombiano sus declaraciones fueron virando, entonces, del culto a la raza criolla

29 The Roanoke World-News, 27 de enero de 1941. The Knoville Journal, 18 de enero de 1941. The Tribune, 20 de diciembre de 1940. 30 El Colombiano, 15 de agosto de 1942.
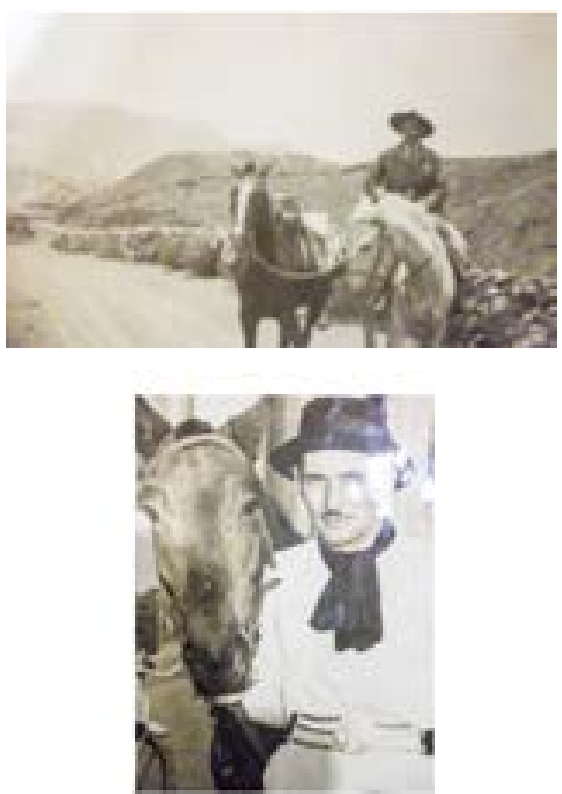

Fuente: Archivo personal del Marcelino Soulé, en Círculo Criollo El Rodeo

y la adulación del caballo argentino hacia la solidaridad latinoamericana expresada en el pueblo de Colombia. El caballo paisa abandonó el anonimato y su figura se hizo visible aún en la prensa argentina que al regreso reconoció la participación en el raíd del gaucho. ${ }^{31}$

\section{El gaucho reconfigurado}

Junto con la reafirmación de la raza criolla, Marcelino Soulé presentaba, recurrentemente, otras intenciones

31 Crítica, 9 de enero de 1943. Noticias Gráficas, 10 de enero de 1943. 
que se evidenciaban desde su discurso. Hacia finales de la década del treinta, la figura del gaucho pampeano como arquetipo de la argentinidad había adquirido un nuevo impulso en orden al movimiento tradicionalista que rescataba su imagen en detrimento de la Buenos Aires cosmopolita (Cattaruzza \& Eujanian, 2003; Casas, 2014). Por esos años, las reivindicaciones no solo se producían desde la sociedad civil, sino que una serie de medidas oficiales erigieron al gaucho como símbolo máximo de la identidad nacional.

Las construcciones para consolidar su figura fueron numerosas y presentaron distintas variantes. La imagen del gaucho traspasó las fronteras del estado-nacional y se difundió en diversas partes del mundo asociado a la región pampeana. Empero, la voz "gaucho" conllevó una disputa por su significado que estaba lejos de subsanarse para los años del raíd. Marcelino Soulé se encargó, a través de la prensa americana, de reafirmar condiciones y características del supuestamente legítimo gaucho argentino:

Sin embargo esa "reafirmación gaucha" operaba también desde las propias editoriales de los periódicos americanos que parecían comulgar con el objetivo de Soulé por delimitar las particularidades de los

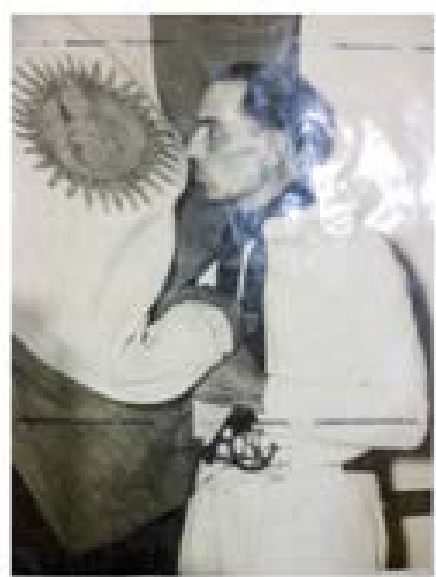

Fuente: Archivo personal del Marcelino Soulé, en Círculo Criollo El Rodeo

hombres de la pampa. Al rememorar la hazaña del raidista, el diario Crítica de Buenos Aires expresaba sobre Marcelino: "Embajador por excelencia de nuestra tierra, el protagonista, el gaucho puro, nacido en la pampa y recocido por el sol... ¿Y qué mejor embajador de lo nuestro que un gaucho a caballo, cuando es un gaucho de verdad?"32 Las manifestaciones como "gaucho puro" o "gaucho de verdad" permiten suponer la circulación de distintas imágenes del gaucho que carecían, según los criterios del periódico, de la legitimidad para portar su nombre. En ese punto Soulé focalizó sus reafirmaciones en detrimento de la figura divulgada por las telenovelas o cantores de tango

32 Crítica, 9 de enero de 1943.

46 El gaucho de América. El raíd de Marcelino Soulé, de Buenos Aires a Washington, 1938-1942 Matías Emiliano-Casas 
que se presentaban en distintas lugares de América.

La supuesta autenticidad del gaucho, la identificación de su figura con la argentinidad, y la permanente necesidad de redefinir sus características, fueron tres ejes estructurales de sus apariciones en los medios gráficos. En diversos pasajes de su viaje, el raidista bonaerense manifestó como uno de sus objetivos primarios: mostrar a los habitantes de los diferentes países "cómo era un gaucho de verdad". ${ }^{33}$ La vestimenta, sus caballos, sus costumbres, pero sobre todo su origen, fueron los argumentos que se presentaban recurrentemente en sus declaraciones.

Cuando Marcelino enunciaba las características que, según él, eran propias de los gauchos argentinos se destacó, en varias oportunidades, el consumo de una infusión que aún goza de vigencia y popular adhesión: el mate. La bebida preparada con hojas secas de una planta que crece en las cuencas de los ríos Paraguay, Paraná, y en el curso superior del río Uruguay -de origen precolombino-, se consolidó como elemento propio de la cultura argentina. Sin embargo, el consumo de esa bebida no se restringió sólo a ese país. En

33 San Antonio Express, 7 de noviembre de 1940.
Uruguay, Paraguay, algunas regiones de Chile y Bolivia, y el sur de Brasil se consume el mate con diferente intensidad y con pequeñas variaciones en su preparación. Soulé se encargó durante sus recorridos periodísticos por los principales periódicos de América de identificar este elemento como constitutivo del gaucho y, si "el gaucho era el arquetipo de la argentinidad", por carácter transitivo de todos los argentinos.

Un reportero de Nuevo Laredo, en el estado de Tamaulipas, al Noroeste mexicano, explicaba, en ocasión de la visita de Marcelino, la composición de la bebida que calificaba como "té de yerbas aromáticas" y se animaba a degustarlo ante el ofrecimiento del argentino. ${ }^{34}$

Soulé fue resignificando la figura del gaucho al galope de sus caballos. En afirmaciones como la vestimenta, la alimentación, y las vicisitudes cotidianas, su discurso respondía al estereotipo forjado por la literatura argentina de fines del siglo XIX y principios del siglo XX. Sin embargo, se advierte en la continuidad de sus afirmaciones una serie de peculiaridades que redefinen las características del hombre de la pampa y se

3425 de octubre de 1941, Nuevo Laredo, México, s/n. Las referencias aparecen también en El Comercio, Quito, 18 de julio de 1939. 
contraponen a elementos que gozaban de cierto consenso para definirlos como propios del gaucho. Aún en la actualidad, cuando los centros tradicionalistas argentinos realizan sus fiestas para "celebrar y honrar la tradición" es común la práctica de alimentarse sólo utilizando el chuchillo porque era la única herramienta que llevaba el gaucho en sus aventuras por la pampa (Ratier, 2001). Empero, Marcelino Soulé no vaciló en hacer referencia a su revólver y catalogarlo como su arma de cabecera durante el raíd. ${ }^{35}$

Otro de las metamorfosis que el raídista fue operando en torno a la figura del gaucho se publicó en el periódico The Tribune de New Orleans que tituló: "Gaucho prefers blonds", afirmando llamativamente la preferencia de los gauchos por las mujeres de cabellos rubios y de ojos celestes bien alejadas de la fisonomía de las "chinas" de la pampa. En el artículo se deja ver a Marcelino fotografiado junto a una mujer norteamericana para graficar "what the gaucho likes": ${ }^{36}$

En relación a la música, si bien Soulé afirmó haber realizado bailes y danzas autóctonas en varias de sus visitas, resaltaban las lamentaciones esbozadas

35 The Knoville Journal, 18 de enero de 1941.

36 The Tribune. 20 de diciembre de 1940.

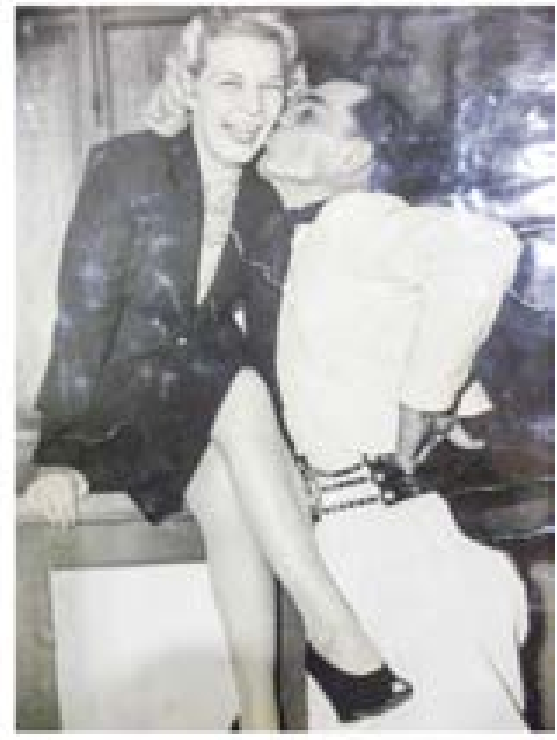

Fuente: Archivo personal del Marcelino Soulé, en Círculo Criollo El Rodeo

por el protagonista en ocasión de no haber llegado a tiempo al concierto de Jaenette MacDonald. ${ }^{37}$ La soprano, de reconocimiento mundial hacia comienzos de la década del cuarenta, no figuraba en el repertorio musical de las jornadas folklóricas ni en las fiestas tradicionalistas.

Marcelino Soulé parecía "forzado" a reconstruir una figura del gaucho aggiornada a los tiempos modernos. Su insistente preocupación por dar cuenta de lo legítimo de su condición, junto con la pretensión de generar la empatía a su paso por los

37 The Roanoke World- News, 27 de enero de 1941.

48 El gaucho de América. El raíd de Marcelino Soulé, de Buenos Aires a Washington, 1938-1942 Matías Emiliano-Casas 
diversos países de América, involucraba una tensión que se manifestó en sus declaraciones. El raidista iba reformulando la imagen del gaucho y construyendo otra a su paso con la persistente colaboración de la prensa que se encargaba de reproducir sus afirmaciones y adoptarlas en sus editoriales. A medida que se alejaba de su ciudad natal y de su agrupación tradicionalista (Marcelino fue socio del Centro Criollo El Rodeo de la Provincia de Buenos Aires), también se alejaba de lo que en esos lugares se representaba con la voz "gaucho".

La pretensión de legitimidad que Soulé acarreaba en su camino, -y el interés por mostrarse como gaucho auténtico-se vio confrontada por sus propias variaciones discursivas. Las declaraciones de Marcelino en referencia a la "pureza" de su condición fueron ratificadas por los cronistas que expresaban: "es un gaucho verdadero" o "el gaucho es legítimo". ${ }^{38}$ Esas manifestaciones daban cuenta de la vigente necesidad de repensar su significado. La prensa americana generalmente exaltaba la figura genuina del raidista en detrimento de los cantores de tango que se "disfrazaban" de gauchos para potenciar sus negocios o de las representaciones que realizaban los actores, ya sea

38 Periódico de Panamá 25 de enero de 1940, s/n. Periódico de Costa Rica, s/d. en las telenovelas como en el cine, y que carecían, acorde a su interpretación de los elementos originales de sus personajes. La coyuntura favorecía las reafirmaciones de Soulé: Rodolfo Valentino con sus películas en la década del veinte, "The Gaucho Serenade" dirigida por Frank MacDonald en 1940, el contacto de Walter Disney con la cultura pampeana, entre otras cosas, hacían del gaucho un personaje atractivo para la época. ${ }^{39}$

La atracción del gaucho también tenía su correlato en los políticos bonaerenses. El raíd de Soulé se integró a un contexto de reivindicación de la tradición rural y del gaucho. Hacia fines de la década del treinta, en Buenos Aires se sancionó la ley que instituyó el Día de la Tradición en la provincia, la "fiesta gaucha por antonomasia". En los fundamentos de la sanción se encontraba la explícita pretensión de consolidar el festejo a nivel nacional y con ello al símbolo gaucho como elemento aglutinador de la identidad argentina.

Empezaba oficialmente, entonces, una compleja búsqueda por integrar al gaucho pampeano como referente

39 Sobre el cine ver Curubeto (1993). Sobre Rodolfo Valentino ver Pujol (1994). Para la relación entre Walter Disney y Florencio Molina Campos ver Gutiérrez Zaldivar (1996). 
también de las culturas del interior del país. Soulé contribuyó a esa operación identificando su figura como lo propio de la Argentina, omitiendo, por ende, las costumbres y referencias propias y diversas que coexistían en el territorio nacional. En el Comercial de Ecuador se publicó: "en el Quito Polo Club...pudimos apreciar las típicas costumbres argentinas con todos sus detalles." 40 En otro ejemplo, el diario Evening Chronicle de Allentown afirmaba que su manera de vestir era la propia de la gente que habitaba en la República Argentina.$^{41}$ En efecto, esto no era así, como tampoco era pertinente presentar la figura del gaucho pampeano como modelo de los habitantes del país. Ese discurso fue sostenido de manera oficial durante la década del treinta y operó como una suerte de actualización del panteón de héroes nacionales patricios que también se había forjado desde Buenos Aires. El recorrido del gaucho por el interior del país fue complejo y presentó respuestas de diversos tipos, desde su integración a las celebraciones y costumbres autóctonas hasta su desconocimiento y rechazo. Lo cierto es que, ante esos intereses, la figura del gaucho se iba reconstruyendo una y otra vez. Sus costumbres, características, sociabilidad, e

40 El Comercial, 18 de julio de 1939.

41 Evening Chronicle, 11 de julio de 1941. ideología, iban mutando acorde a las pretensiones que estuvieran en juego. En Marcelino Soulé y la prensa americana que cubrió su prolongado camino se advertía un claro ejemplo de esos cambios.

\section{Conclusiones}

El viaje de Soulé se inscribió en un clima de época que colocaba a la cuestión del gaucho en el centro de numerosos debates. Las medidas oficiales habían generado adeptos y detractores y la puja por el significado, la historicidad y la vigencia del símbolo se manifestaba recurrentemente. Desde allí, se puede advertir que el raíd aventurero no emergió como una idea suelta de un sujeto en busca de reconocimiento, sino que se insertó en un contexto propicio para la reafirmación de las características del gaucho. En Argentina, además del impulso oficial, se gestaban agrupaciones que adoptaban las posturas tradicionalistas. En el extranjero, como ya se ha mencionado, la difusión de ciertas representaciones del gaucho a través de diversas manifestaciones artísticas hacía de éste un personaje llamativo que ameritaba su presencia en los medios periodísticos.

La repercusión de Marcelino en la prensa americana se tornaba inteligible desde dos dimensiones: en

50 El gaucho de América. El raíd de Marcelino Soulé, de Buenos Aires a Washington, 1938-1942 Matías Emiliano-Casas 
primer lugar, la convocatoria de la figura del gaucho y la "necesidad" de certificar su correspondencia o no con los representaciones artísticas; en segundo lugar, la participación activa de Soulé que se hacía presente en las oficinas de prensa. De hecho, en algunos artículos se aclaraba: "hemos recibido la visita" o "pasó por nuestra redacción". ${ }^{42}$ Se considera que los recurrentes encuentros con los periodistas, que transcurrían generalmente entre intercambios amistosos de costumbres y ofrecimientos del gaucho a degustar sus mates, resultaron fundamentales para comprender la intensa difusión de su raíd.

Otro de los puntos emergentes en el análisis del recorrido remite a la falta de precisión de los medios que cubrieron el trayecto. El contraste de los artículos permite identificar una serie de imprecisiones llamativas que se exacerbaron a partir de las declaraciones del protagonista. En ese orden, el trayecto transitado, las cualidades del jinete y hasta la participación de los caballos criollos se entramaron en una narrativa de equívocos y exageraciones que obstaculizaban la reconstrucción fidedigna del viaje.

42 Por ejemplo, Noticias, México, 9 de octubre de 1940.
Las contradicciones en cuanto a la información no impidieron distinguir una práctica recurrente en el camino de Soulé. El raidista, resignificando algunas costumbres, pero sobre todo los gustos y entretenimientos del gaucho argentino, constituyó una muestra de la continua búsqueda por definir su significado. Sus variaciones se comprenden mejor cuando se atienden las diferentes posturas que circulaban en Argentina para la época. Un artículo periodístico de la Revista Atlantida -una publicación de interés general con una tirada masiva- en 1942 no dudaba en categorizar al gaucho como: "sucio, inútil y petulante, descomedido, escandaloso, ratero y haragán", ${ }^{43}$ lo que despertó la veloz intervención del Gobierno Nacional exigiendo una retractación en referencia a sus apreciaciones sobre "la figura más noble y más auténticamente nacional" ${ }^{44}$ Esa tensión, que representaba solo un ejemplo, permite comprender las licencias que Marcelino se concedió a la hora de reconfigurar al gaucho. Si bien sostuvo una perspectiva "positiva", exaltando siempre su carácter y consolidándolo como sinónimo de argentinidad, no vaciló en recodificar sus gustos. En varias ocasiones,

43 Revista Atlantida, julio de 1943.

44 Comunicado oficial de la Presidencia de la Nación para la Revista Atlantida. 10 de julio de 1943. Archivo de Agrupación Bases. 
dejó de manifiesto las preferencias del gaucho argentino por el cine de Hollywood y por sus actores, lo que resultaba incongruente con los discursos que lo erigían como elemento aglutinador de la identidad nacional en detrimento de lo foráneo. ${ }^{45}$

La inestabilidad que caracterizaba al término "gaucho" permitió también que se lo simplifique considerándolo desde la prensa norteamericana como sinónimo de cow-boy. El San Antonio Express de Texas, por ejemplo, aseguraba: "Dressed as a gaucho, wich means cow-boy in Argentina". ${ }^{46}$ En efecto, más allá de los puntos de contacto que podrían llegar a evidenciarse, como sus actividades rurales y su devenir frente al proceso de modernización (Carretero, 1964, pp. 92-94), el gaucho estaba atravesado por las disputas semánticas en torno de su figura. Esa característica lo convertía en ícono plausible de ser apropiado en pos de diversos intereses, reconfigurando una y otra vez sus atributos.

En la tarea conjunta que desarrollaron Marcelino Soulé y la prensa americana se evidenció cómo el pretendido símbolo de la argentinidad, que ya era oficialmente reconocido

45 The Roanoke World-News, 27 de enero de 1941.

46 San Antonio Express, 7 de octubre de 1940. al menos en la Provincia de Buenos Aires, carecía de una definición sólida y excluyente, sino más bien resultaba producto de diversas, y por momentos contrapuestas, atribuciones.

\section{Bibliografía}

Assunção, F. (2007). Historia del Gaucho. El gaucho: Ser y Quehacer (2 ed.) Buenos Aires: Claridad.

Ballent, A. y Adrián Gorelik A. País urbano o país rural: La modernización territorial y su crisis. En Nueva Historia Argentina. Buenos Aires: Sudamericana. 1998-2005. (2001). Buenos Aires: Sudamericana.

Béjar, M. (2005). El régimen fraudulento; la política en la Provincia de Buenos Aires, 1930-1943. Buenos Aires: Siglo XXI.

Berger, P. y Luckmann T. (1999). La construcción social de la realidad. Trad. Silvia Zulueta. Rev. Marcos Giménez Zapiola. Buenos Aires: Amorrutu editores.

Borges, J. Martínez Estrada, E. y Leumann, C. (1980). Martín Fierro y su crítica. Buenos Aires: Centro Editor de América Latina.

Buchrucker, C. (1999). Nacionalismo y peronismo; la Argentina en la crisis ideológica mundial. Buenos Aires: Sudamericana.

Casas, M. (2014). La Fiesta de la Tradición. Las primeras celebraciones oficiales al gaucho como símbolo de la identidad argentina, Buenos Aires, 1939-1940.

52 El gaucho de América. El raíd de Marcelino Soulé, de Buenos Aires a Washington, 1938-1942 Matías Emiliano-Casas 
En A. Bisso et.al (comps.) Formas políticas de celebrar y conmemorar el pasado (1930-1943). pp. 136-154. Ceraunia. La Plata.

Cattaruzza, A. y Eujanian A. (2003). Políticas de la historia, Argentina 1860 1960. Buenos Aires-Madrid: Alianza Editorial.

Cattaruzza, A. (2007). Los usos del pasado. Buenos Aires: Sudamericana.

Curubeto, D. (1993). Babilonia Gaucha. Buenos Aires: Ediciones Planeta.

Devoto, F. "El revés de la trama: políticas migratorias y prácticas administrativas en la Argentina (1919-1949)", en Desarrollo económico, vol. 41, ${ }^{\circ}$ 162, julio-septiembre de 2001, pp. 281-304.

Devoto, F. (2002). Nacionalismo, fascismo y tradicionalismo en la Argentina moderna. Buenos Aires: Siglo veintiuno.

Floria, C. (2010). El pensamiento de los nacionalistas. Buenos Aires: El Ateneo.

Fradkin, R. (2003) Centaures de la pampa. Le gaucho, entre l'histoire et le mythe en Annales HSS, janvier-fevrier $\mathrm{N}^{\circ} 1$.

Güiraldes, R (1926). Don Segundo Sombra. Buenos Aires: Colombo.

Gutiérrez Zaldivar, I. (1996). Molina Campos. Buenos Aires: Zurbaran Ediciones.

Halperín Donghi, T. (1985). José Hernández y sus mundos. Buenos Aires: Ediciones Sudamericana.
Hernandez, J. (1972). Martín Fierro. Buenos Aires: Imprenta de La Pampa.

Hobsbawm, E. y Ranger, T. (comp.) (1983). La Invención de la Tradición. Barcelona: Crítica.

Lugones, L. (1944). El Payador (2ª ed.) Buenos Aires: Centurión.

Ludmer, J. (2000). El género gauchesco. Un tratado sobre la patria. Buenos Aires: Perfil.

Lvovich, D. (2003) Nacionalismo y antisemitismo en Argentina. Buenos Aires: Ediciones B Argentina.

Míguez, E. (2005) El Mundo de Martín Fierro. Buenos Aires: Eudeba.

Obligado, R. (1888). Santos Vega. Tradiciones Argentinas. Buenos Aires: Pedro Irume.

Portugal, J. (2007). Las novelas de José María Arguedas: Una incursión en lo inarticulado. Lima: Editorial Fondo PUCP.

Prieto, A. (1988). El discurso criollista en la formación de la Argentina moderna, Buenos Aires: Editorial Sudamericana.

Pujol, S. (1994). Valentino en Buenos Aires. Buenos Aires: Emece.

Ratier, H., Del Campo, E., Etchichury, L., Iriberry, M. (2001). "Organizaciones rurales y cultura de las pampas: la construcción social de lo gauchesco y sus implicaciones". Ponencia presentada en la IV Reunión de Antropología del Mercosur. Curitiba. Brasil. 
Reitano, E. (2010) El gobierno de Manuel Fresco en la Provincia de Buenos Aires (1936-1940). La Plata: Instituto Cultural de la Provincia de Buenos Aires.

Rojas. Ricardo. El pensamiento vivo de Sarmiento. Buenos Aires: Losada, 1941.

Rojas, R. (1909) La Restauración Nacionalista. Buenos Aires: Ministerio de Justicia e Instrucción Pública.

Roldán, B. (1925). Poesías Completas. Buenos Aires: El Ateneo.

Sarmiento, D. (1845). Civilización y barbarie. Vida de Juan Facundo Quiroga. Santiago de Chile: Imprenta del progreso.

Schvartzman, J. (2013). Letras gauchas. Buenos Aires: Eterna Cadencia.

Schwarzstein, D. (1997). "Actores sociales y política inmigratoria en la Argentina. La llegada de los republicanos españoles", en Estudios Migratorios Latinoamericanos, $\mathrm{n}^{\circ} 37$, pp. 423-446

Senkman, L. (1991). Argentina, la Segunda Guerra Mundial y los refugiados indeseables,

Terrrera, G. (1969). El caballo criollo en la tradición argentina. Buenos Aires: Círculo Militar. 